UDC 613.2

DOI: 10.21668/health.risk/2019.1.17.eng

\title{
TECHNIQUES FOR DETERMINING PHTHALATES IN FOOD PRODUCTS AIMEd FOR INFANTS' NUTRITION: An OVERVIEW
}

\author{
T.S. Ulanova, T.D. Karnazhitskaya, A.S. Zorina \\ Federal Scientific Center for Medical and Preventive Health Risk Management Technologies, 82 Monastyrskaya Str., \\ Perm, 614045, Russian Federation
}

Phthalates (esters of phthalic acid) are widely used as plasticizers in polymer materials production and it has resulted in substantial contamination with phthalates as they occur in environmental objects, food products, drinking waters, and human biological media. Toxic effects produced by phthalates lead to functional disorders in the endocrine system and synthesis of insulin, phthalates have reproductive toxicity, they cause allergenic reactions and bronchial asthma in children as well as some other diseases. Food products are a primary source of influences exerted by phthalates on population health, first of all, children. To assess risks related to adverse effects by phthalates on children, it is necessary to obtain data on concentrations of these substances in food products aimed for children nutrition. In order to work out a highly sensitive and selective technique for determining phthalates in children nutrition, the authors performed an overview of scientific and technical literature that focused on techniques for determining phthalates in products for infant nutrition (milk mixtures, milk cereals, and canned meat). It was detected that gas and liquid chromatography together with mass spectrometry were widely applied to analyze phthalates in children nutrition; several techniques were applied for samples preparations to exert direct influence on measurements sensitivity and precision. It is still vital to determine how to efficiently extract phthalates with conventional and up-to-date extraction techniques and how to purify them from complicated food matrixes, first of all, milk and vegetable fats that can be found in products aimed for children nutrition. There is a still a problem related to secondary contamination of samples with phthalates due to their occurrence in the air inside laboratories, reagents, solvents, etc., and it needs to be solved. Basing on the analysis of all the reviewed data, we can conclude that it is necessary to work out highly sensitive, selective, and highly precise techniques for determining phthalates in products aimed for children nutrition with new methodical tools for samples preparation taking into account a matrix effect which is specific for certain products as well as risks related to secondary contamination of samples in the process of their preparation and analysis.

Key words: phthalates, food products, milk mixtures, canned meat, gas and liquid chromatography, massspectrometry, samples preparation.

Phthalates (esters derived from o-phthalic acid) are widely spread contaminants; they are identified as endocrine-disrupting chemicals. Phthalates are applied as plasticizers for polymer materials based on polyvinyl chloride (PVC), polystyrene, and rubbers; they products with mass fracture of polymers in their structure being equal to $15-40 \%$ more flexible and durable. There are no any chemical bonds between phthalates and polymers and the former are washed out of plastic products during their use. People, especially younger children, are exposed to phthalates primarily due to their occurrence in food products $[1,2,3]$.

Exposure to phthalates results in hormonal and metabolic disorders, development defects, deviations in the reproductive system functioning, and other diseases [4, 5]. Bis(2-ethylhexyl phthalate) is considered to be "a possible human carcinogen" by the International Agency for Research on Cancer [5].

Over the last decades there has been extensive research on assessing health risks caused by exposure to phthalates; fixing permissible daily consumption of individual

(C) Ulanova T.S., Karnazhitskaya T.D., Zorina A.S., 2019

Tat'yana S. Ulanova - Doctor of Biological Sciences, Professor, head of Chemical and Analytical Research Department (e-mail: ulanova@fcrisk.ru; tel.: +7 (342) 233-10-37).

Tatyana D. Karnazhitskaya - Candidate of Biological Sciences, Head of the Laboratory for Liquid Chromatography Techniques (e-mail: tdkarn@fcrisk.ru; tel.: +7 (342) 233-10-37; ORCID: https://orcid.org/0000-0001-6768-0045).

Anastasia S. Zorina - chemist at the Laboratory for the Liquid Chromatography Techniques (e-mail: root@fcrisk.ru; ORCID: https://orcid.org/0000-0002-4276-9921). 
phthalates; determining phthalates concentrations in food products, drinking water, the atmospheric air and air inside buildings, and other media. Speaking about impacts exerted by phthalates on children's health, especially infants and children younger than 3 , we should mention one of the most vital lines of research, namely monitoring over contamination of milk and milk products (powder-like and liquid milk mixtures and milk cereals) as they are the only nutrition suitable for infant children and children younger than 3 .

The paper dwells on surveying various techniques for determining phthalates in food products for younger children's nutrition (milk mixtures, milk cereals, and canned meat). Primarily our attention is paid to techniques applied to prepare samples for instrumental analysis and to reduce risks of secondary contamination with phthalates which can happen to analyzed samples.

Phthalates were first determined in food products more than 50 years ago $[6,7]$. As it was not the case with other chemical contaminants, data on phthalates concentrations in food products were rather limited due to problems related to methodical support and high phthalates concentrations in field blanks; the latter was caused by laboratory environment, reagents, and materials being contaminated with these chemicals.

According to the Sanitary-epidemiologic rules 2.3.2.1940-05 food products made for younger children's nutrition are food products that can be consumed by children from their birth to 3 years as their structure and properties correspond to physiological peculiarities that children have at this age [8]. Food products for younger children are substitutes for breast milk made from animal milk or vegetable raw materials (cow's milk, soya proteins, etc.) as well as food products introduced into children's daily ration during their first year of life in addition to breast milk or its substitutes; such products are made of animal and/or vegetable raw materials and they can be either purees or dried mixtures.

In spite of multiple works focusing on methodical approaches to determining phtha- lates in food products from various categories, there are very few data on how to analyze them in food products for younger children; basically any data we could find concern phthalates occurrence in various food products made for common nutrition. Thus, scientific and technical information that can be found on SciensDirect web-site reveals that only 356 works out of total 7,343 containing such key words as "determination of phthalates" and published over the last 5 years dealt with analyzing phthalates in children nutrition [9].

Over the last years such techniques as liquid and gas chromatography together with mass spectrometry have been applied to quantitatively determine phthalates mixture in food products, including those aimed for children's nutrition; they allow to successfully resolve issues related to measuring techniques being sensitive and selective. Apart from mass spectrometric detectors, gas chromatography is accomplished with flame ionizing detectors and electronic capture [10]; highperformance liquid chromatography is applied to analyze phthalates with ultrasound and fluorimetric detectors [10].

Capillary gas chromatography (GC) with subsequent mass spectrometric detection (MS) of analytes (GC-MS) is most frequently applied to perform instrumental analysis of phthalates [11]. A most widely applied technique in gas chromatography analysis of phthalates in food products is derivatization (primarily etherification); it is done in order to make analyzed compounds more volatile as phthalates boil at rather high temperature (from $284{ }^{\circ} \mathrm{C}$ to $490.6{ }^{\circ} \mathrm{C}$ ), and chromatographic separation on capillary columns is limited to $280{ }^{\circ} \mathrm{C}-300{ }^{\circ} \mathrm{C}[12,13]$. As a result, sample preparation becomes more complicated and, consequently, there are higher risks of secondary contamination and a decrease in determination sensitivity.

Ion traps (IT), single quadruple (Q), and triple quadruple (QQQ) are used as mass analyzers in gas chromatography. Phthalates molecules are fragmented with electronic ionization (EI) and as a result a fragmented ion is 
formed with its mass-to-charge being equal to $149 \mathrm{~m} / \mathrm{z}$, and this ion is common for most phthalates. It imposes certain limits on applying GC-MS for analyzing mixtures that contain phthalates and their isomers, first of all, due to joint elution of analytes with the same mass but different molecule structure $[14,15]$.

Liquid chromatography/mass spectrometry (LC-MS) is an alternative for GC-MS. Tandem quadruple mass spectrometer provides high selectivity, especially when separating phthalates isomers, and sensitivity of determination [3, 14, 16-18]. Electrospray ionization (ESI) is most frequently applied to ionize phthalates; in few cases chemical ionization is applied for the purpose [16]. Positive ionization mode is usually applied to analyze phthalates diethers while negative ionization one provides better sensitivity for detecting monophthalates [19]. A basic issue which arises in analyzing phthalates in food products for children with LC-MS with electrospray ionization is how to achieve ion signals inhibition related to use of buffers in analysis with interfering influences exerted by components of sample matrix and poor chromatographic separation. To resolve it, various strategies can be applied, for example, improved procedures for samples treatment and/or higher resolution of chromatographic separation [3]. High performance LC-MS and LC-MS-MS are rarely used as liquid chromatographers are more prone to contamination than gas ones due to greater number of potential contamination sources such as solvents applied for extraction and chromatographic separation, chemical reagents, filters, tubes, etc. [20, 21].

To analyze 27 phthalates in milk and dairy products, experts applied a relatively innovative analytic procedure, high-performance liquid chromatography with quick resolution together with a mass-spectrometric detector with an Orbitrap (UHPLC-Q-Orbitrap) in electrospray ionization mode. The authors pointed out that if an orbit ion trap was applied, accompanying matrix compounds could be easily excluded out of analysis and it facilitated phthalates identification and quantitative determination [22].
Mass-spectrometric detectors applied in gas and liquid chromatography to quantitatively determine phthalates in food products for children are mostly calibrated with internal standard and more rarely with absolute calibration; it is due to complex sample preparation that includes multi-stage procedures for extracting and purifying an obtained extract from matrix components. There are several compounds which are most frequently used as internal standards; they are deuterated compounds such as $\mathrm{d}^{10}$-phenanthrene, $\mathrm{d}^{4}$-di(2ethylhexyl) phthalate or $\mathrm{d}^{4}$-dibutyl phthalate, as well as non-deuterated ones, for example, benzyl butyl phthalate (BBP), anthracene, pyrene, or dibutyl adipate (DBA) [16]. In some research individual deuterated internal standards are applied for each analyzed phthalate which proves that various phthalates behave differently during extraction and further treatment of an obtained extract [16].

Sample preparation that includes analytes extraction out of matrix and extract purification from interfering influences exerted by accompanying components is a significant stage in analyzing phthalates in food products for children as sensitivity and precision of determining phthalates concentrations depends on efficient selective extraction of analytes. Methodical and scientific-technical literature describes a great variety of techniques for phthalates extraction and it proves that the task is truly complicated and far from being solved completely. Most techniques are aimed at phthalates determination in breast milk [23-26], milk mixtures for children [27-30], and natural milk [22]. There are very few works on analysis of phthalates in milk cereals and canned meat, and we can say there are one or two papers that dwell on determining phthalates in food products for children which are consumed by them during their first year of life in addition to breast milk [29, 13]. Practically every published research work confirms that food products for children are contaminated with phthalates.

At present, to extract phthalates out of food products which are a complex multicomponent biological sample, the following 
techniques can be applied: liquid-liquid extraction (LLE) [25, 31-34], headspace-solid phase micro-extraction (HS-SPME) [35], diffusion solid phase extraction QuEChERS [22], solid phase extraction (SPE) [23], automated online solid phase extraction $[23,36]$. Some of them have certain limits, for example, high variability of results due to unstable quantity of components in composure of samples from one matrix; necessity to purify extracts thoroughly in order to prevent contamination of analytical equipment and it takes a lot of time to do it; complexity related to separating an extract and a product matrix after extraction; application of complex sample preparation which is not quite relevant for a routine analysis procedure.

Liquid extraction accompanied with extracts being purified from milk fats is the most widely used procedure for extracting phthalates out of milk and milk mixtures. Most authors prefer to use acetonitrite as a solventextractant among polar and non-polar organic solvents applied in extraction procedures for organic compounds [13, 22]. In some cases extraction is then followed by a sample being dried and then repeatedly dissolved in a solvent suitable for a research procedure; there can also be re-extraction in order to further purify an extract. Due to some additional procedures, concentrations of certain phthalates go up, for example, there is an increase in dibutyl phthalate (DBP) and bis(2-ethylhexyl) phthalate (BEHP) in field blanks, and it results in a procedure being less sensitive.

Direct extraction of phthalates out of food products for children via solid phase extraction with automated systems usually involves secondary contamination of analyzed samples and field blanks in the same way as with other sample preparation techniques [26, 33].

Liquid extraction is applied to purify extracts from fats, proteins, and other matrix components. When analyzing phthalates in milk and milk products, including milk mixtures and milk cereals, researchers successfully purify an acetonitrite extract with hexane; the procedure is based on better solubility of phthalates in acetonitrite, and milk fats, in hexane. Depending on how contaminated extracts are with animal and vegetable fats, the authors recommend to perform re-extraction twice or three times [37].

Size-exclusion chromatography (SEC) is frequently applied as a purification procedure after liquid extraction of milk samples [24] and milk mixtures [29]. When samples are purified with it, phthalates concentration in field blanks is determined within a range from $0.1 \mu \mathrm{g} / \mathrm{kg}$ to several $\mu \mathrm{g} / \mathrm{kg}$.

Size-exclusion chromatography (gel chromatography) based on separating molecules from various compounds as per their size means that big molecules can't penetrate sorbent pores and elute earlier than smaller molecules which can penetrate pores and remain on a sorbent. This technique is more and more frequently seen as an efficient sample preparation procedure for determining organic contaminants in lipid matrices. Phthalates with molecular masses within 200 to 4000 Daltons range are separated from lipids with molecular mass about 800 Daltons on GPC columns. classic GPC separation is performed on big columns being $400 \mathrm{~mm}$ long and having an internal diameter equal to $25 \mathrm{~mm}$ under low pressure and operating speed being $5 \mathrm{ml} / \mathrm{min}$ [38, 39]. An example when size-exclusion chromatography was successfully applied for analyzing phthalates is a procedure for purifying an extract from milk fat with gelpenetration chromatography (GPC). An extract that contained phthalates and milk fat was fractioned on S-X3 zeolite under eluting with a mixture of cyclohexane and ethyl acetate, the volume ration of solvents being 9:1. Two fractions F1 and F2 (Figure1) that contained substances being analyzed were collected separately; F1: 43-50 minutes, and F2: 50-82 minutes; concentrated to a volume equal to $1 \mathrm{~cm}^{3}$ in nitrogen flow and directly analyzed with gas chromatography with mass spectrometry (GC-MS).

Size-exclusion chromatography can be miniaturized and it significantly reduces consumption of solvents. When equipment for HPLC is applied (isocratic pump, auto-sampler able to introduce a sample with its volume 


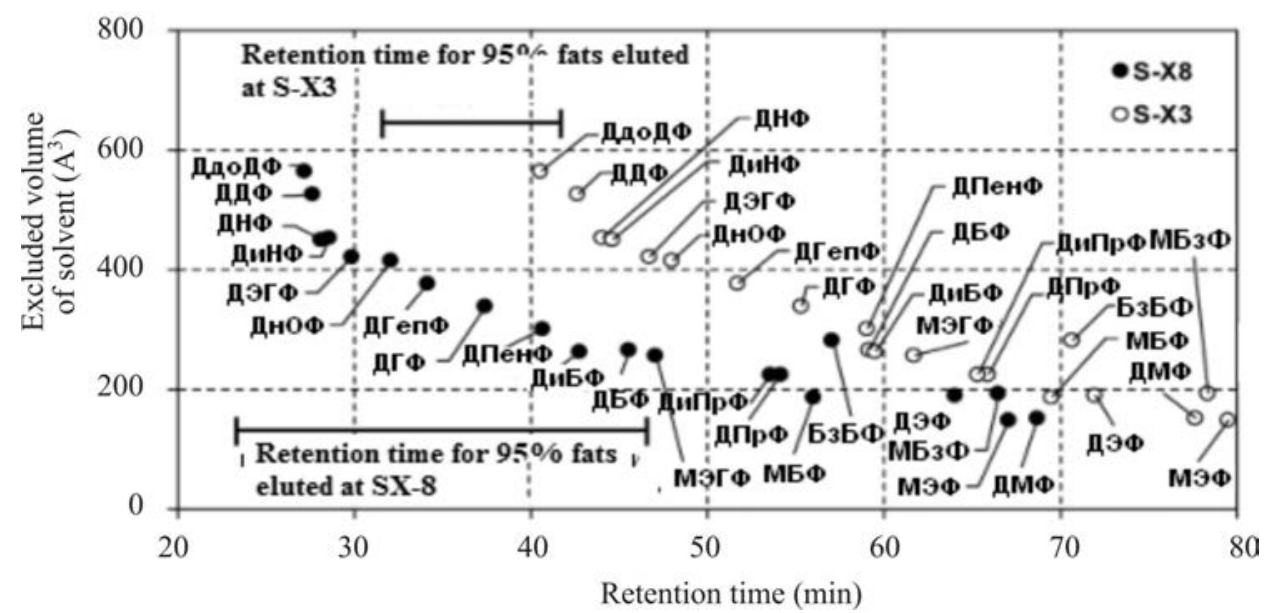

Figure 1. Retention time (min) for di-ethers and mono-ethers of o-phthalic acid on S-X8 and S-X3 zeolites under eluting with a mixture of cyclohexane and ethyl acetate, the volume ration of solvents being 9:1 at a speed equal to $4.5 \mathrm{~cm}^{3} / \mathrm{min}$ : МЭФ is mono-ethyl phthalate, МБзФ is mono-benzyl phthalate, МБФ is mono-butyl phthalate, МЭГФ is mono-(2-ethylhexyl) phthalate, ДМФ is di-methyl phthalate, ДЭФ is di-ethyl phthalate, ДПрФ is di-propyl phthalate, ДиПрФ is di-isopropyl phthalate, БзБФ is benzyl butyl phthalate, ДБФ is di-butyl phthalate, ДиБФ is di-isobutyl phthalate, ДПенФ is dipentyl phthalate, ДГекс $\Phi$ is di-hexyl phthalate, ДГеп $\Phi$ is di-heptyl phthalate, ДнОФ is di-n-octyl phthalate, ДЭГФ is bis-(2-ethylhexyl) phthalate, ДиНФ is di-isononyl phthalate, ДНФ is di-nonyl phthalate, ДДФ is di-decyl phthalate, ДдоДФ is di-dodecyl phthalate

being up to $500 \mu 1$, column thermostat, UV-detector with variable wave length, and a device to collect fractions), separation is performed at a speed equal to $1 \mathrm{ml} / \mathrm{min}$ with dichloromethane on a column which is $300 \mathrm{~mm}$ long and has an internal diameter equal to $7.5 \mathrm{~mm}$, with sorbent particles sized $5 \mu \mathrm{m}$ and pores size being equal to 5 nanometers. Pores size equal to 5 nanometers matters a lot as it allows to separate organic compounds with their masses within 100-1000 range. Better resolution is achieved when two columns are used.

Feng Y., Zhu J., Sensenstein R. examined how to apply headspace solid phase microextraction (HS-SPME) in order to exclude milk fat out of samples before GC-MS when analyzing phthalates in milk. The procedure is based on creating a vapor phase above a milk sample when it is being heated in a hermetic vessel, absorption of analyzed phthalates extracted into a vapor phase on poly-dimethylsiloxane fiber and thermodesorption of analytes directly into a chromatographic column of a gas chromatographer for analysis. The researchers reported that extraction took a long time (the shortest extraction period lasted for
60 minutes at $90{ }^{\circ} \mathrm{C}$ ). Detection limits for phthalates varied from $0.1 \mu \mathrm{g} / \mathrm{kg}$ to $100 \mu \mathrm{g} / \mathrm{kg}$ depending on how fat milk samples were. When extraction on SPME fiver was performed, milk fats were absorbed together with phthalates, and there were a lot of interfering peaks detected on a chromatograph in analysis of a sample with gas chromatography [35].

QuEChERS technique applied for extracting and purifying when phthalates are detected in cow's milk allows to achieve smaller secondary contamination at a level lower than $1 \mu \mathrm{g} / \mathrm{kg}$ [22].

We analyzed methodical and scientific literature that focused on techniques for phthalates determination in food products consumed by children in addition to breast milk during the first year of life and revealed that there were very few works that dwelled on phthalates determination in canned meat and milk cereals for children. Phthalates are usually determined in canned meat for children nutrition with gas and liquid chromatography; the procedure involves chemical analysis of a mixture that includes three biological matrices, a meat one (protein compo- 
nent of food), fat-containing one (fats in a product), and cereal-fruit-vegetable one (carbohydrates); each matrix, on one hand, has a complicated multi-component structure, but on the other hand, it has its specific peculiarities related to a chemical structure of a product.

According to the State Standard R 546282011 "Food products for children nutrition. Canned meat. Puree for younger children. Technical conditions", the following raw materials can be used to manufacture canned meat:

- meat (beef, veal, pork, rabbit meat, and others);

- oil (sunflower, soya, or corn oil; butter), lard;

- starch (potato, corn, or rice one);

- salt and water.

$100 \mathrm{~g}$ of canned meat that can be given to children starting from the 4th month of life contain 2.5-3.0 g of proteins, 2.6-3.0 g of fats, and 6.7-9.3 $\mathrm{g}$ of carbohydrates recalculated as per dry weight; $100 \mathrm{~g}$ of canned meat mixed with cereals and vegetables and aimed for children aged from 6 months to 1 year contain 2.5-9.8 g of proteins, 3.0-9.5 $\mathrm{g}$ of fats, and 2.9-8.0 g of carbohydrates recalculated as per dry weight. Component structure that analyzed products have exerts its influence on a sample preparation procedure, background contamination level, and, consequently, on sensitivity and precision of measurement procedures aimed at determining phthalates concentrations in food products for younger children's nutrition.

M. Russo et al. applied GC-MS procedure to determine 6 phthalates (DMP, DEP, DBP, DiBP, BBP, and DEHP) in food products for children (canned puree for children made of chicken and rabbit meat as well as freeze-dried samples of chicken, turkey, sea bream, and flatfish); they applied liquid-liquid extraction to extract target components with heptane with a sample being treated with ultrasound. The authors describe a problem related to preparing puree samples: intense mixing led to formation of a jelly-like emulsion, and it was next to impossible to extract an organic phase out of it thus blocking any further extraction. Developers of the procedure explain it through occur- rence of surfactants which are usually added to stabilize a product. To solve the problem, it was suggested to freeze-dry children nutrition before extraction and purification. Each sample was dried out for 4 hours at $-52{ }^{\circ} \mathrm{C}$ and pressure being equal to $0.08 \mathrm{mbar}$ in a device aimed for freeze-drying. The authors recommend to add $\mathrm{NaCl}$ solution into samples and treat them with ultrasound as it can help to destruct the emulsion. When conditions were optimized, phthalates extraction amounted to $96.2-109.2 \%$ with extraction inaccuracy being equal to $\leq 10,5 \%$, and the bottom detection limit being $20 \mu \mathrm{g} / \mathrm{kg}$ [13].

Petersen J. and Breindahl T. focus on phthalates determination with GC-MS in 11 various products for younger children (fruit, cereals, rice mixed with fruit, or meat mixed with vegetables). To prepare samples, the authors applied liquid-liquid extraction with pentane and then purified an obtained extract with a mixture of ethyl acetate/cyclohexane (1:1); a supernatant (pentane extract) was further purified with gelpenetration chromatography (GPC), dried, and re-dissolved for being analyzed with chromatomass-spectrometry. Detection limits for DBP, BBP, and DEHP amounted to 0.35, 0.015 and $0.25 \mu \mathrm{g} / \mathrm{kg}$ respectively, extraction degree varied from 76 to $128 \%$ [29].

So, it is rather difficult to prepare samples of children nutrition for analyzing phthalates concentrations in them with chromato-massspectrometry (both GS-MS and LC-MS); in addition to that, an issue related to secondary contamination of samples with analyzed compounds during their preparation and analysis hasn't been resolved yet. Phthalates are widely spread in the environment and they can be detected practically in any piece of laboratory equipment and in the air inside any laboratory. Given that, practically all the researchers who deal with phthalates pay their special attention to this issue and try out to develop and recommend various measures aimed at reducing background contamination with phthalates in laboratories, air inside them, equipment, reagents, solvents, laboratory vessels and materials.

Thus, Bubba M., Ancillotti C., Checchini L. suggest to analyze phthalates in a clean room 
equipped with high-performance filters that purify air with absorbed carbon. Excess pressure should be maintained within the room in order to avoid any air contamination from outside. Special attention is paid to purification of reagents which is performed as follows: first, sodium chloride is heated for 12 hours at $450{ }^{\circ} \mathrm{C}$ in a muffler and kept in a glass bottle until it is used. Anhydrous sodium sulfate and fiberglass filters are also treated and kept at $150{ }^{\circ} \mathrm{C}$ before application. Aluminum oxide is purified under $450{ }^{\circ} \mathrm{C}$ for a night and then applied immediately. Distilled water of HPLC range is purified with hexane for three times. Cyclohexane is treated with purified aluminum oxide ( $30 \mathrm{~g}$ of $\mathrm{Al}_{2} \mathrm{O}_{3}$ per a liter of solvent) via manual shaking during $30 \mathrm{sec}$ and then it passes through a purified fiberglass filter. Glass vessels are washed before application with hot potassium hydroxide solution in methanol, hot chrome mixture, and purified water, and then they are dried completely under $300{ }^{\circ} \mathrm{C}$ for an hour. Glass vessels for taking and preparing milk samples are washed with isopropyl alcohol before application. As a result, when breast milk samples and milk mixtures were analyzed, DiBP concentration in field blanks (samples without milk or milk products which underwent the complete sample preparation procedure) amounted to 0.79-1.08 $\mu \mathrm{g} / \mathrm{kg}$; DBP one, $0.27-0.36 \mu \mathrm{g} / \mathrm{kg}$; and DEHP one, $0.88-1.14 \mu \mathrm{g} / \mathrm{kg}$; against $18-25$ $\mu \mathrm{g} / \mathrm{kg}$ for DiBP, $6.2-11 \mu \mathrm{g} / \mathrm{kg}$ for DBP, and 18 $75 \mu \mathrm{g} / \mathrm{kg}$ DEHP in the analyzed samples [12].

Ren $R$. notes that there is a potential risk of secondary contamination at any stage in an analytical procedure including sampling, preparing a food product sample for analysis, and chromatographic analysis itself. In order to reduce contamination of materials with phthalates, various purification procedures are suggested. In most cases it is recommended to treat all glass units (sampling containers, pipettes, volumetric flasks, centrifuge vials, and other laboratory vessels) which are applied during analysis; they should be thoroughly washed in strong oxidizers and rinsed with organic solvents before application. The authors of the paper usually keep clean vessels under $400{ }^{\circ} \mathrm{C}$ for 8 hours, wash them in hexane for
12 hours and then dry at $120^{\circ} \mathrm{C}$ before application. Field blanks are analyzed with gas chromatography-mass spectrometry techniques simultaneously with samples of artificial milk mixtures so that probable secondary contamination of samples that occurs when samples are being prepared for analysis is taken into account. DEHP was the single phthalate out of 17 which was detected in field blanks in a concentration equal to $3.2 \mu \mathrm{g} / \mathrm{kg}$ [33].

As a rule, thorough treatment of laboratory equipment, vessels, auxiliary materials, reagents and solvents reduces phthalates concentration in field blanks which are usually samples prepared for analysis but without any contents of examined products in them, but it can't completely resolve an issue related to secondary contamination of analyzed samples. It is obligatory to analyze field blanks for each series of analyzed samples in order to take into account background contents when calculating ultimate phthalates concentrations in food products.

A lot of researchers note that background contamination can probably be decreased via reducing a number of procedures applied to prepare samples for analysis [10, 20, 33].

So, all the accomplished research on examining and analyzing methodical approaches to phthalates determination in food products for younger children indicate that it is vital to develop highly sensitive, selective, and highprecision determination procedures taking into account interfering influences exerted by component structure of matrices which are specific for a specific food product. To achieve as complete extraction of analyzed compounds as possible, it is necessary to apply new sample preparation procedures which should be simplified as regards extraction and purification of complicated matrices such as milk, milk mixtures, or canned meat; it is also advisable to apply reliable techniques aimed at reducing background influences exerted by phthalates which are present everywhere in the environment.

Funding. The research was not granted any sponsor support.

Conflict of interests. The authors state there is no any conflict of interests. 


\section{References}

1. Yen T., Lin-Tan D.-T., Lin J.-L. Food safety involving ingestion of foods and beverages prepared with phthalate-plasticizer-containing clouding agents. Journal of the Formosan Medical Association, 2011, no. 110, pp. 671-684.

2. Fasano E., Bono-Blay F., Cirillo T., Montuori P., Lacorte S. Migration of phthalates, alkylphenols, bisphenol A and di(2-ethylhexyl)adipate from food packaging. Food Control, 2012, no. 27, pp. $132-138$.

3. Gallart-Ayala H., Nunez O., Lucci P. Recent advances in LC-MS analysis of food-packaging contaminants. Trends in Analytical Chemistry, 2013, no. 27, pp. 99-124.

4. Gupta R. Reproductive and developmental toxicology editor, second edition. - KY, Breathitt Veterinary Center, Murray State University, Hopkinsville Publ., 2017.

5. Eveillard A., Mselli-Lakhal L., Mogha A., Lasserre F., Polizzi A., Pascussi J. Di-(2-ethylhexyl)-phthalate (DEHP) activates the constitutive androstane receptor (CAR): A novel signaling pathway sensitive to phthalates. Biochemical Pharmacology, 2009, no. 77, pp. 1735-1746.

6. Cerbulis J., Ard J. Method for isolation and detection of dioctyl phthalate from milk lipids // Association of Official Analytical Chemists, 1967, no. 50, pp. 646-650.

7. Williams D. Gas chromatographic determination of low levels of di-(2-ethylhexyl)phthalate in soy oil. Association of Official Analytical Chemists, 1973, vol. 56, no. 1, pp. 181-183.

8. Sanitarno-epidemiologicheskie pravila i normativy SanPiN 2.3.2.1940-05. Prodovol'stvennoe syr'e i pishchevye produkty. Organizatsiya detskogo pitaniya (s izmeneniyami na 27 iyunya 2008 goda). Available at: https://base.garant.ru/12138699 (10.11.2018).

9. ScienceDirect. Available at: https://www.sciencedirect.com (17.08.2018).

10. Leo M. Analysis of Endocrine Disrupting Compounds in Food. Iowa: Blackwell Publ., 2011, $491 \mathrm{p}$.

11. Wei T. Analysis of phthalates in foods by using gas chromatography mass-spectrometry (GC-MS). Researhc report submitted in fulfillment of the requirements for the degree of master of science. Department of chemistry, Faculty science Universiti of Malaya Publ., Kuala Lumpur, 2014, p. 53.

12. Bubba M., Ancillotti C., Checchini L, Fibbi D., Rossini D., Ciofi L., Rivoira L., Profeti C., Orlandini S., Furlanetto S. Determination of phthalate diesters and monoesters in human milk and infant formula by fat extraction, size-exclusion chromatography clean-up and gas chromatographymass spectrometry detection. Journal of Pharmaceutical and Biomedical Analysis, 2018, no. 148, pp. 6-16.

13. Russo M., Avino P., Notardonato I. Fast analysis of phthalates in freeze-dried baby foods by ultrasound-vortex-assisted liquid-liquid microextraction coupled with gas chromatography-ion trap/mass spectrometry. Journal of Chromatography A, 2016, no. 1474, pp. 1-7.

14. Hu J., Feng T., Li W., Zhai H., Liu Y., Wang L., Hu C., Xie M. Surface molecularly imprinted polymers with synthetic dummy template for simultaneously selective recognition of nine phthalate esters. Journal of Chromatography A, 2014, no. 1330, pp. 6-13.

15. Llompart M., Celeiro M., Lamas J., Sanchez-Prado L., Lores M., Garcia Jares C. Analysis of plasticizers and synthetic musks in cosmetic and personal care products by matrix solid-phase dispersion gas chromatography-mass spectrometry. Journal of Chromatography A, 2013, no. 1293, pp. 10-19.

16. Gonzalez-Salamo J., Socas-Rodriguez B., Hernandez-Borges J. Analytical methods for the determination of phthalates in food. Current Opinion in Food Science, 2018, no. 22, pp. 122-136.

17. Masia A., Moliner-Martinez Y., Munoz-Ortuno M., Pico Y., Campíns-Falco P., Multiresidue analysis of organic pollutants by in-tube solid phase microextraction coupled to ultra-high performance liquid chromatography-electrospray-tandem mass spectrometry. Journal of Chromatography A, 2013, no. 1306, pp. 1-11.

18. Xu D., Deng X., Fang E., Zheng X., Zhou Y., Lin L., Chen L., Wua M., Huang Z. Determination of 23 phthalic acid esters in food by liquid chromatography tandem mass spectrometry. Journal of Chromatography A, 2014, no. 1324, pp. 49-56. 
19. Tranfo G., Papaleo B., Caporossi L., Capanna S., De Rosa M., Pigini D., Corsetti F., Paci E. Urinary metabolite concentrations of phthalate metabolites in Central Italy healthy volunteers determined by a validated HPLC/MS/MS analytical method. International Journal of Hygiene and Environmental Health, 2013, vol. 216, pp. 481-485.

20. Yang J., Li Y., Wang Y., Ruan J., Zhang J., Sun C. Recent advances in analysis of phthalate esters in foods. Trends in Analytical Chemistry, 2015, no. 72, pp. 10-26.

21. Hayasaka Y. Analysis of phthalates in wine using liquid chromatography tandem mass spectrometry combined with a hold-back column: Chromatographic strategy to avoid the influence of pre-existing phthalate contamination in a liquid chromatography system. Journal of Chromatography A, 2014, no. 1372, pp. 120-127.

22. Jia W., Chu X., Ling Y., Huanga J., Chang J. Analysis of phthalates in milk and milk products by liquid chromatography coupled to quadrupole Orbitrap high-resolution mass spectrometry. Journal of Chromatography A, 2014, no. 1362, p. 110-118.

23. Calafat A., Slakman A., Silva M., Herbert A., Needham L. Automated solid phase extraction and quantitative analysis of human milk for 13 phthalate metabolites. Journal of Chromatography $A, 2004$, vol. 805, no. 1, pp. 49-56.

24. Hogberg J., Hanberg A., Berglund M., Skerfving S., Remberger M., Calafat A., Filipsson A., Jansson B., Johansson N., Appelgren M., Håkansson H. Phthalate diesters and their metabolites in human Breast milk, blood or serum, and urine as biomarkers of exposure in vulnerable populations. Environmental Health Perspectives, 2008, vol. 116, no. 3, pp. 334-339.

25. Mortensen G., Main K., Andersson A., Leffers H., Skakkebæk N. Determination of phthalate monoesters in human milk, consumer milk, and infant formula by tandem mass spectrometry (LC-MS-MS). Analytical and Bioanalytical Chemistry, 2005, vol. 382, no. 4, pp. 1084-1092.

26. Zimmermann S., Gruber L., Schlummer M., Smolic S., Fromme H. Determination of phthalic acid diesters in human milk at low ppb levels. Food Additives \& Contaminants: Part A, 2012, vol. 29, no. 11 , pp. $780-1790$.

27. Bradbury J. UK panics over phthalates in baby milk formulae. Lancet, 1996, no. 347, pp. 1541.

28. Bradley E., R. Burden, Leon I., Mortimer D., Speck D., Castle L. Determination of phthalate diesters in foods. Food Additives \& Contaminants: Part A, 2013, no. 30, pp. 722-734.

29. Petersen J., Breindahl T. Abstract in total diet samples, baby food and infant formulae. Food Additives \& Contaminants: Part A, 2000, vol. 17, no. 2, pp. 133-141.

30. Tsumura Y., Ishimitsu S., Kaihara A., Yoshii K., Tonogai Y. Phthalates, adipates, citrate and some of the other plasticizers detected in Japanese retail foods: a survey. Journal of Health Sciences, 2002, no. 48, pp. 493-502.

31. Cirillo T., Latini G., Castaldi M., Dipaola L., Fasano E., Esposito F., Scognamiblio G., Francesco F., Codellis L. Exposure to Di-2-Ethylhexyl Phthalate, Di-n-Buthyl Phthalate and Bisphenol through infant formulas. Journal of Agricultural and Food Chemistry, 2015, no. 63, pp. 3303-3310.

32. Ge V., Yang X., Wu X., Wang Z., Geng W., Guo C. Phthalate residue in goat milk-based infant formulas manufactured in China. Journal of Dairy Science, 2016, vol. 99, no. 10, pp. 7776-7781.

33. Ren R., Jin Q., He H., Bian T., Wang S., Fan J. Determination of 17 phthalate esters in infant milk powder and dairy products by GC-MS with 16 internal standards. Chromatographia, 2016, no. 13-14, pp. 903-910.

34. Sorensen L. Determination of phthalates in milk and milk products by liquid chromatography/tandem mass spectrometry. Rapid Communications in Mass Spectrometry, 2006, vol. 20, no. 7, pp. 1135-1143.

35. Feng Y., Zhu J., Sensenstein R. Development of a headspace solid-phase microextraction method combined with gas chromatography mass spectrometry for the determination of phthalate esters in cow milk. Analytica Chimica Acta, 2005, vol. 538, no. 1-2, pp. 41-48.

36. Lin S., Ku H., Su P., Chen J., Huang P., Angerer J., Wang S. Phthalate exposure in pregnant women and their children in central Taiwan. Chemosphere, 2011, vol. 82, no. 7, pp. 947-955. 
37. Tienpont B. Determination of Phthalates in Environmental, Food and Biomatrices - An Analytical Challenge. Department of Organic Chemistry Ghent University, 2004. Available at: http://www.researchgate.net/publication/267703038 (17.08.2018).

38. Specht W., Tilkes M., Frezenius Z. Gas-chromatographische Bestimmung von Rückständen an Pflanzenbehandlungsmitteln nach Clean-up über Gel-Chromatographie und Mini-KieselgelSäulen-Chromatographie. Analytical Chemistry, 1980, no. 301, 300 p.

39. Thier H., Zeumer H. Manual of Pesticide residue Analysis. VCH, Weinheom, 1987, vol. 1, pp. 75.

Ulanova T.S., Karnazhitskaya T.D., Zorina A.S. Techniques for determining phthalates in food products aimed for infants' nutrition: an overview. Health Risk Analysis, 2019, no. 1, pp. 154-163. DOI: 10.21668/health.risk/2019.1.17.eng

Received: 21.01.2019

Accepted: 11.03.2019

Published: 30.03.2019 